\title{
Permeação cutânea in vitro do ácido kójico
}

\author{
Mayumi Eliza Otsuka Sato, Fernanda Gomara, Roberto Pontarolo, Itamar Francisco Andreazza, \\ Mariella Zaroni*
}

Departamento de Farmácia, Setor de Ciências da Saúde, Universidade Federal do Paraná

* Correspondência:

Mayumi Eliza Otsuka. Sato

Laboratório de Tecnologia

Farmacêutica

Universidade Federal do Paraná

Av. Pref. Lothário Meissner, 3400 80210-170 - Curitiba - PR, Brasil

E-mail: mayumi@ufpr.br
Desordens no processo melanogênico podem causar as hiperpigmentações, sendo a de maior freqüência o melasma. $O$ ácido kójico é um dos despigmentantes tópicos utilizados no tratamento destas hipercromias. A ação de um produto dermatológico deve ser tópica, não devendo atingir níveis sistêmicos. Um dos fatores que pode definir o nível de ação, tópica ou sistêmica, são os excipientes das formulações. Neste contexto, o presente trabalho teve por objetivo avaliar o grau de permeação cutânea in vitro, utilizando célula de FRANZ modificada, de uma formulação em relação a uma solução tampão $\mathrm{pH}$ 7,4, ambas contendo ácido kójico na concentração de $2 \%$. A quantificação do ácido kójico permeado e retido na membrana foi realizada por método espectrofotométrico no ultravioleta. O estudo in vitro mostrou que a absorção do ácido kójico da formulação apresentou cinética de pseudo $1^{a}$ ordem (no intervalo de 1 a 8 horas) e, conseqüentemente, menor fluxo através da membrana natural (pele da orelha de porco) e maior retenção cutânea, enquanto que o ácido kójico da solução tampão pH 7,4 apresentou cinética de ordem zero e, conseqüentemente, maior fluxo e menor retenção. Este resultado indicou que a formulação desenvolvida mostrou-se adequada para a veiculação do ácido kójico, tendo em vista que o órgão alvo é a pele.
Unitermos

- Permeação cutânea in vitro

- Ácido kójico

- Despigmentante

\section{INTRODUÇÃO}

Em um mundo cada vez mais globalizado e competitivo, a aparência física tornou-se um aspecto de grande importância na sociedade contemporânea. As manchas da pele, principalmente as faciais, não são estéticas e causam alguns transtornos que dificultam o bem-estar do indivíduo no âmbito psicossocial.

As hiperpigmentações são, em geral, distúrbios ca- racterizados pelo aumento de melanina e outros pigmentantes na pele. Os principais desencadeadores são as radiações solares, os hormônios sexuais e agentes externos, fontes de radicais livres.

Neste contexto, tanto indústrias de cosméticos quanto farmacêuticas têm crescido a cada ano, diversificando suas matérias-primas e ampliando suas linhas de produtos disponíveis ao consumidor.

Atualmente, a tecnologia farmacêutica tem dado 
especial atenção à avaliação da eficácia terapêutica do produto acabado. Um produto não estável e com dosagem incorreta, pode proporcionar uma ação medicamentosa inadequada. Vários fatores podem ser responsáveis por esta falha na atividade do produto, como por exemplo, os fatores fisiológicos, os quais dependem, na maioria das vezes, do paciente ou do substrato. Entretanto, existem vários fatores inerentes ao próprio fármaco, à forma farmacêutica, à formulação e ao processo tecnológico de fabricação, que influem, quase sempre de forma direta e expressiva, na disponibilidade dos medicamentos.

As características de liberação de um fármaco a partir de um veículo dermatológico podem ser avaliadas determinando-se o coeficiente de partição óleo/água. Entretanto, estudos de liberação in vitro e in vivo proporcionam dados mais significativos.

Durante a fase de desenvolvimento de produtos dermatológicos é adequado empregar procedimentos de liberação in vitro para selecionar excipientes para as formulações que possam proporcionar uma atividade terapêutica adequada. Pode-se considerar que os estudos de liberação medicamentosa proporcionam dados valiosos sobre as particularidades estruturais do veículo e a capacidade deste em liberar os fármacos.

Com base nas colocações acima e na importância das substâncias despigmentantes na atualidade, o objetivo do presente trabalho foi desenvolver uma formulação semi-sólida adequada para o ácido kójico e avaliar a retenção e permeação cutânea por metodologia in vitro.

\section{MATERIAL E MÉTODOS}

\section{Material}

O material objeto de estudo foi o ácido kójico Sigma Aldrich Chem. Co, Coréia, incorporado em uma emulsão não iônica composta dos seguintes excipientes: hidroxietilcelulose (Natrosol ${ }^{\circledR} 250$ HHR) - Amerchol, USA; dipropilenoglicol - Coréia; metilparabeno $\left(\right.$ Nipagin $\left.^{\circledR}\right)$ - Brasfanta, Brasil; triglicerídeos do ácido cáprico e caprílico (Crodamol ${ }^{\circledR}$ GTCC) - Croda, Brasil; cera autoemulsionante não-iônica (Emulgade wax ${ }^{\circledR} \mathrm{GP}$ ) Cognis, Brasil; ácido etilenodiaminotetracético dissódico (EDTA-Na $)$ - DEG, Brasil; butil-hidroxitolueno (BHT) - Rússia.

\section{Métodos}

\section{Formulação em estudo}

Foi preparada uma emulsão O/A não-iônica, com espessantes graxos e poliméricos, empregando-se técnicas usuais. Na Tabela I consta a formulação em estudo.

TABELA I - Formulação em estudo

\begin{tabular}{lc}
\hline Componentes & Concentração (\%) \\
\hline Ácido kójico & 2 \\
Hidroxietilcelulose & 0,5 \\
Dipropilenoglicol & 8 \\
Metilparabeno & 0,2 \\
Triglicerídeos do ácido & 10 \\
$\quad$ cáprico e caprílico & 15 \\
Cera autoemulsionante não-iônica & 0,2 \\
Ácido etilenodiaminotetracético & \\
$\quad$ dissódico & 0,2 \\
Butil-hidroxitolueno & \\
\hline
\end{tabular}

Anteriormente ao preparo das formulações, as matérias-primas bem como a formulação selecionada para estudo de permeação cutânea in vitro, tiveram sua qualidade avaliada segundo parâmetros especificados em compêndios oficiais.

\section{Quantificação do ácido kójico nos ensaios de permeação e retenção cutânea in vitro}

Para a quantificação do ácido kójico nos ensaios empregou-se metodologia por espectrofotometria no ultravioleta no comprimento de onda de $269 \mathrm{~nm}$ (espectrofotômetro Shimadzu 1606), segundo Gomara et al. (2004).

\section{Permeação cutânea in vitro do ácido kójico}

A célula de difusão in vitro consistiu de um compartimento receptor de $7 \mathrm{~mL}$, uma área disponível para a difusão de $1,77 \mathrm{~cm}^{2}$, acoplados a um sistema de agitação magnética de 6 séries (Permeagear). O sistema de difusão encontrava-se acoplado a um banho-maria, termostatizado (Marconi) com circulação externa para a manutenção da temperatura em $37{ }^{\circ} \mathrm{C}(\mathrm{OECD}, 2004)$. No estudo foi empregada membrana natural (pele dissecada da orelha de porco, sem pêlo e sem o tecido subcutâneo e gorduroso presente abaixo da derme).

A solução tampão fosfato $\mathrm{pH} 7,4$ foi colocada no compartimento receptor. Sobre a extremidade das células foram esticadas as membranas, com a derme voltada para a solução receptora. Espalharam-se uniformemente sobre toda a área da membrana 2,0 $\mathrm{g}$ da formulação contendo $2 \%$ de ácido kójico.

A permeação desta formulação foi comparada à permeação de $2 \mathrm{~mL}$ de solução tampão fosfato $\mathrm{pH} 7,4 \mathrm{com}$ ácido kójico na concentração de $20 \mu \mathrm{g} / \mathrm{mL}$. 
O sistema de agitação foi acionado e amostras de $1,0 \mathrm{~mL}$ da fase receptora foram coletadas nos tempos de $5,10,15,20,25,30,60,120,180,240,300,360,420,480$, $540,600,660$ e 720 minutos. Na determinação da permeação de ácido kójico a partir da solução tampão fosfato $\mathrm{pH} \mathrm{7,4} \mathrm{as} \mathrm{alíquotas} \mathrm{da} \mathrm{fase} \mathrm{receptora} \mathrm{foram}$ coletadas somente até 480 minutos. Para manter o volume constante, a cada coleta foi reposto ao sistema $1,0 \mathrm{~mL}$ da solução receptora. O experimento foi realizado em triplicata e como controle foi realizado um branco contendo 2,0 g de formulação isenta de ácido kójico.

Para o cálculo da quantidade permeada (Q), considerou-se as diluições que ocorreram após a primeira coleta, empregando-se a fórmula abaixo descrita, segundo Aronson (1993) e Bentley e Fonseca (2002):

$\mathrm{Q}_{\text {real }, \mathrm{t}}=\mathrm{C}_{\text {mensurado, } \mathrm{t}} \cdot \mathrm{V}_{\mathrm{r}}+\Sigma^{\mathrm{n}-1} \cdot \mathrm{C}_{\mathrm{a}} \cdot \mathrm{V}_{\mathrm{a}}$ onde:

$\mathrm{Q}$ - quantidade permeada acumulada

$\mathrm{Q}_{\text {real, }}=\mathrm{o}$ valor real no tempo $\mathrm{t}$

$\mathrm{C}_{\text {mensurada }}=$ concentração mensurada da coleta no tempo $\mathrm{t}$ $\mathrm{V}_{\mathrm{r}}=$ volume da solução receptora da célula de difusão

$\mathrm{C}_{\mathrm{a}}=$ concentração da amostra removida

$\mathrm{V}_{\mathrm{a}}=$ volume da amostra removida

A quantidade de ácido kójico permeado foi determinado por espectrofotometria no ultravioleta, comprimento de onda de $269 \mathrm{~nm}$ a partir de uma curva padrão de ácido kójico $(1,2,3,4,5,10,15,20$ e $25 \mu \mathrm{g} / \mathrm{mL})$ em tampão fosfato $\mathrm{pH} 7,4$. Para esta análise, as alíquotas das soluções receptoras, removidas das células de difusão foram diluídas (1:5) com tampão fosfato $\mathrm{pH} 7,4$.

Os dados de permeação cutânea obtidos foram utilizados para calcular os parâmetros cinéticos como tempo de latência (tempo LAG) e fluxo (J) do ácido kójico através da membrana. Para determinar a cinética foram utilizados o modelo cinético de Higuchi (pseudo $1^{\mathrm{a}}$ ordem) (Michniak, Chapman, Seyda, 1993), o de $1^{\text {a }}$ ordem e o de ordem zero. O modelo que apresentou o coeficiente de correlação linear mais próximo de 1 correspondeu à cinética da permeação da substância ativa. A interceptação no eixo das abcissas desta curva, em regressão linear, representou o tempo LAG em minutos. O fluxo (J) foi obtido pela inclinação da curva (Florence, Atwood, 2003). O parâmetro LAG foi expresso em minutos e J foi expresso em $\mu \mathrm{g} / \mathrm{cm}^{2} /$ minutos.

\section{Retenção cutânea in vitro do ácido kójico}

A extração do ácido kójico retido na pele de orelha de porco, foi baseada no método proposto por Sasaki et al. (1991) e Tauber e Toda (1976). Decorridas 12 horas de permeação in vitro, a pele da orelha de porco foi retirada do aparelho de difusão. A área da pele exposta à permeação foi limpa com solução de metanol, recortada, pesada e picotada. Os fragmentos obtidos foram triturados com $25 \mathrm{~mL}$ de metanol, em homogeneizador de tecidos (Ultra Turrax Ika) até a total dilaceração da pele. A suspensão resultante foi submetida à sonicação em ultra-som para o rompimento das células. O produto obtido foi filtrado para um balão volumétrico de $50 \mathrm{~mL}$ e o volume completado com solução de metanol.

Paralelamente, efetuaram-se os mesmos ensaios, empregando a pele de orelha de porco triturada em metanol e com a fita adesiva, também em solução de metanol, para averiguar se os mesmos não apresentavam interferentes para a quantificação do ácido kójico.

A quantidade de ácido kójico presente nesta solução foi determinada por espectrometria no ultravioleta $(269 \mathrm{~nm})$ tanto para a formulação em estudo, como para a solução tampão fosfato $\mathrm{pH} 7,4$ com ácido kójico. O mesmo procedimento foi efetuado com a formulação e com solução tampão fosfato $\mathrm{pH} 7,4$, isentas de ácido kójico. Para a quantificação foi construída uma curva analítica de ácido kójico em metanol nas concentrações de 5, 10, 20, $30,40,50,60,70 \mu \mathrm{g} / \mathrm{mL}$.

\section{RESULTADOS E DISCUSSÃO}

\section{Formulação em estudo}

A escolha de um sistema adequado para incorporação de fármacos é de fundamental importância para a estabilidade, para a disponibilidade no local de aplicação e, conseqüentemente, para a obtenção dos efeitos esperados. $\mathrm{O}$ veículo tem influência na absorção do fármaco, tendo um papel dominante na terapia tópica (Florence, Atwood, 2003).

As emulsões são os veículos mais usuais de sistemas de liberação em produtos de uso tópico. Por meio destas, é possível veicular ampla gama de substâncias que são liberadas de maneira rápida e conveniente (Schueller, Romanowski, 2000).

Para a veiculação do ácido kójico elaborou-se uma emulsão não-iônica, pois são adequadas para produtos com pH ácido. A base não-iônica escolhida foi o Emulgade wax, que forma redes de cristais líquidos pela formação de uma série de bicamadas lamelares de moléculas de emulsificante ao redor das gotículas de óleo (Paludetti, 1995; Lachmann, Lieberman, Kanig, 2001).

Apesar das ceras autoemulsionantes apresentarem em sua composição os agentes de consistência, muitas vezes há a necessidade de se adicionar estes com a finalidade de melhorar a estabilidade e a aplicabilidade. Os agentes de consistência usualmente empregados são de 
natureza graxa ou polimérica (Sanctis, 2000). Deste modo, na formulação escolhida optou-se pela incorporação de hidroxietilcelulose (Natrosol $250^{\circledR} \mathrm{HHR}$ ) devido ao caráter não-iônico.

Como emoliente, foi empregado o Crodamol ${ }^{\circledR}$ GTCC que consiste de mistura de triglicerídeos de cadeia média, principalmente dos ácidos cáprico e caprílico. Segundo Sanctis (2000), este componente apresenta composição lipídica semelhante à da pele humana, reforçando o seu emprego.

Os conservantes usuais incluem dentre outros o metilparabeno (Ansel, Popovich, Allen, 2000), o qual foi empregado na formulação na concentração de $0,2 \%$. E, com a finalidade de evitar o ressecamento das formulações e evitar a perda de água da pele, adicionou-se como agente umectante o dipropilenoglicol, tradicionalmente empregado com esta finalidade (Sanctis, 2000).

Os processos de oxidação foram prevenidos com a adição do butil-hidroxitolueno (BHT), e de agentes seqüestrantes como o ácido etilenodiaminotetracético (EDTA). O uso do EDTA também potencializa a ação do conservante pela quelação de metais essenciais ao crescimento de microrganismos (Aulton, 2005).

\section{Permeação cutânea}

A administração de produtos medicamentosos pela via cutânea destina-se à obtenção, tanto de uma ação tópica como sistêmica, sendo primordial que se tenha uma concreta definição de qual destas ações é desejada, visto que os critérios para avaliação destes produtos são conceitualmente diferentes. De um produto dermatológico destinado ao tratamento de patologias cutâneas, exige-se a retenção do fármaco na pele, com pequeno ou inexistente fluxo através dela (Shah, Elkins, Skelly, 1992b).

O ácido kójico tem ocupado posição de destaque entre as substâncias usadas para o clareamento de vários tipos de hipercromias cutâneas (Batistuzzo, Itaya, Eto, 2006). Entretanto, ao lado da atividade tópica, não existem estudos demonstrando efeitos sistêmicos e colaterais decorrentes de sua absorção.

$\mathrm{Na}$ avaliação de produtos de ação dermatológica e transdérmica, testes clínicos podem ser precedidos, e em algumas vezes substituídos, por testes in vitro. Estes testes, devido às suas peculiaridades, permitem entender alguns fenômenos que ocorrem entre a aplicação do produto e o efeito medido farmacologicamente, de maneira prática, rápida e sem a interferência de fatores biológicos (Shah, Maibach, 1993).

Para o estudo, foi utilizada a célula de difusão baseada no modelo de Franz, usualmente empregada em estu- dos de permeação cutânea in vitro de produtos tópicos (Smith, Haigh, 1989).

A eleição de uma solução receptora para os experimentos in vitro depende da solubilidade do fármaco. Como o ácido kójico é muito solúvel em água, a solução receptora mais indicada é a solução tampão $\mathrm{pH} 7,4$. A manutenção das sink conditions foi necessária para garantir a obtenção de resultados efetivos (Shah, Maibach, 2003).

A membrana é outro fator crítico na condução dos experimentos de permeação in vitro. As membranas sintéticas não possuem as propriedades anatômicas e fisiológicas da pele, assim, o ideal é realizar estes estudos com membranas naturais (pele humana e de animais). A pele humana decididamente é a mais adequada para estudos in vitro. Entretanto, a dificuldade na aquisição deste tecido e a variação biológica levaram ao emprego de peles de animais (Bronaugh, Stewart, 1986).

A pele da orelha de porco tem sido muito utilizada nos experimentos in vitro, apesar de apresentar algumas diferenças anatômicas quando comparada com a pele humana. A viabilidade de aquisição, a melhor uniformidade das amostras, bem como a facilidade de dissecação e separação do tecido subcutâneo, contribuíram para a eleição desta pele como modelo de membrana para o estudo de permeação (Reifenrath et al., 1984; Sato et al., 1991).

Segundo Shah et al. (1992) quando o material a ser empregado é semi-sólido o espalhamento de quantidade finita deste produto dificilmente produziria uma camada uniforme sobre a membrana, sendo que nestas situações é aconselhável o uso de "dose infinita", ou seja, excesso de produto.

Para os ácidos fracos com pKa maiores que 7,5 e bases com pKa menores que 5, a absorção cutânea é independente do pH (Florence, Atwood, 2003). Deste modo, como o pKa do ácido kójico é de 7,90 a 8,03, não há interferência do $\mathrm{pH}$ do meio, comprovado por meio de ensaios prévios (Gomara, 2003).

A base dos experimentos in vitro de permeação cutânea é determinar as pequenas quantidades de fármaco que atravessam as membranas ou que ficam retidos nas mesmas. A utilização de um método analítico sensível, o qual viabilizasse o experimento, foi de extrema importância. Entre os dois métodos analíticos desenvolvidos para a quantificação do ácido kójico, o método espectrométrico no ultravioleta mostrou-se mais sensível que o método colorimétrico por cloreto férrico (Gomara et al., 2004). No entanto, o método espectrométrico no ultravioleta não é adequado quando a formulação apresenta o conservante metilparabeno em sua constituição, devido à absorção do ácido kójico ocorrer no mesmo comprimento de onda 
(269 nm). Para evitar que os resultados obtidos fossem equivocados foi utilizada a formulação isenta de conservante no ensaio.

Para a determinação da quantidade de ácido kójico permeada foi utilizada uma curva padrão de ácido kójico em tampão fosfato $\mathrm{pH} 7,4$, obtida em comprimento de onda de $269 \mathrm{~nm}$.

A Figura 1 mostra o perfil de permeação do ácido kójico, presente na formulação e na solução tampão fosfato $\mathrm{pH} 7,4$, através de pele da orelha de porco.

A quantidade de ácido kójico permeada através da membrana foi significativamente $(\mathrm{p}<0,01)$ maior na solução tampão fosfato pH 7,4 do que na formulação (Figura 1).

Em relação à formulação, apesar do perfil de permeação do ácido kójico demonstrar que o fluxo estabilizou após 360 minutos (6 horas), ou seja, à medida que a concentração do fármaco diminui o fluxo tende a diminuir, pode-se verificar que a quantidade de fármaco permeado é muito pequena em relação ao conteúdo da formulação (Figura 1).
Estas alterações no fluxo possivelmente estejam ocorrendo devido a diferença na liberação do fármaco. Provavelmente, ocorre maior permeação do fármaco que está em contato direto com a membrana.

No perfil de permeação do ácido kójico presente na formulação observa-se que o fluxo permanece contínuo, demonstrando que existe quantidade infinita sendo fornecida à membrana e que a velocidade de cedência do fármaco provavelmente se mantém constante (Figura 1).

Como as velocidades de liberação, e conseqüentemente de permeação, variam de acordo com as características da formulação, foi observado um aumento no tempo necessário para que o fluxo da formulação se equilibre (tempo LAG) em relação ao da solução tampão fosfato $\mathrm{pH}$ 7,4 (Figura 2) (Shah et al., 1992). O tempo LAG da formulação foi de 8 minutos enquanto que da solução tampão foi de 3 minutos (Figura 2).

Decorrido o tempo LAG, é possível definir a cinética de permeação cutânea do produto (Bronaugh, Maibach, 1999).

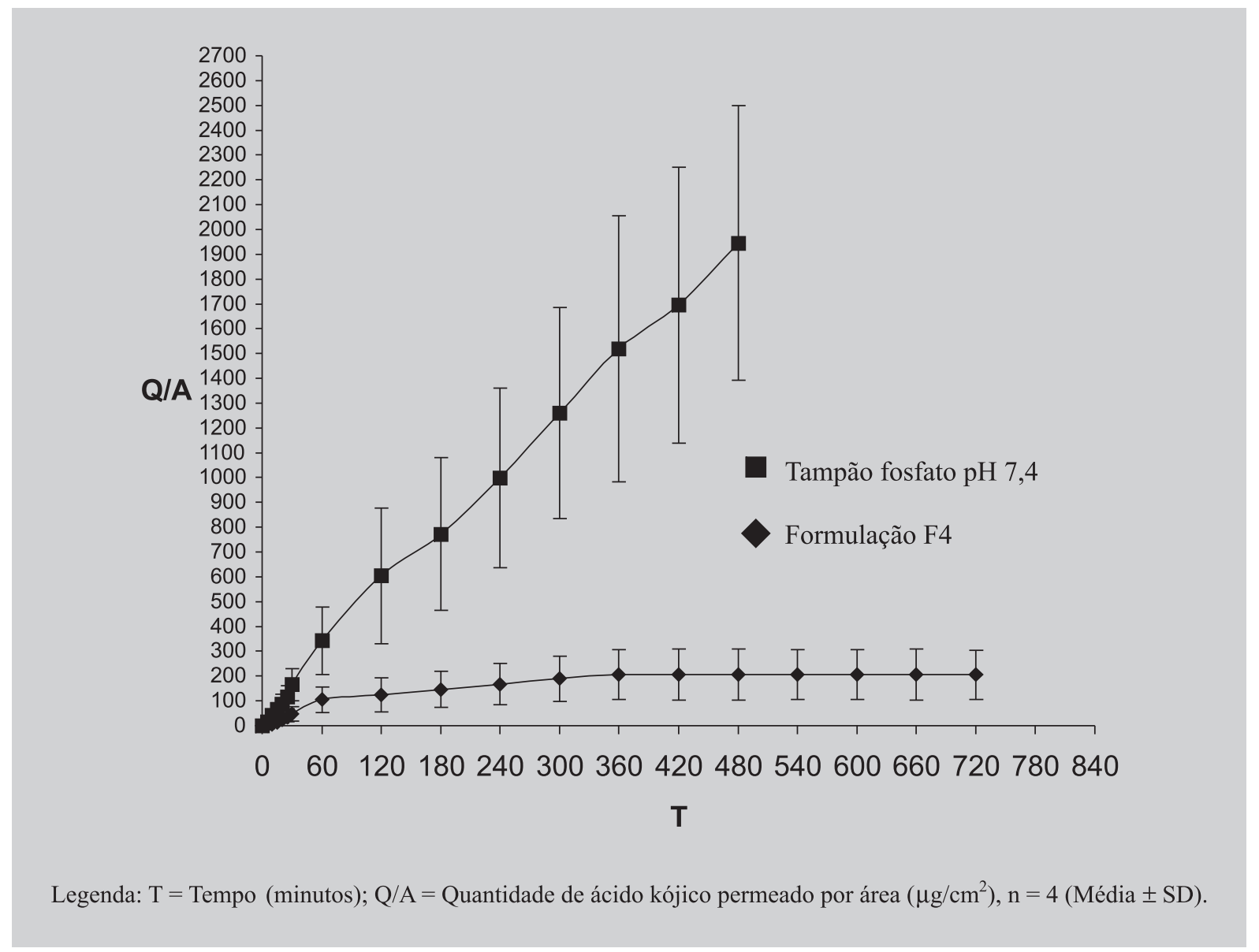

FIGURA 1 - Perfil de permeação cutânea in vitro do ácido kójico da formulação e do tampão fosfato pH 7,4, na pele da orelha de porco. 


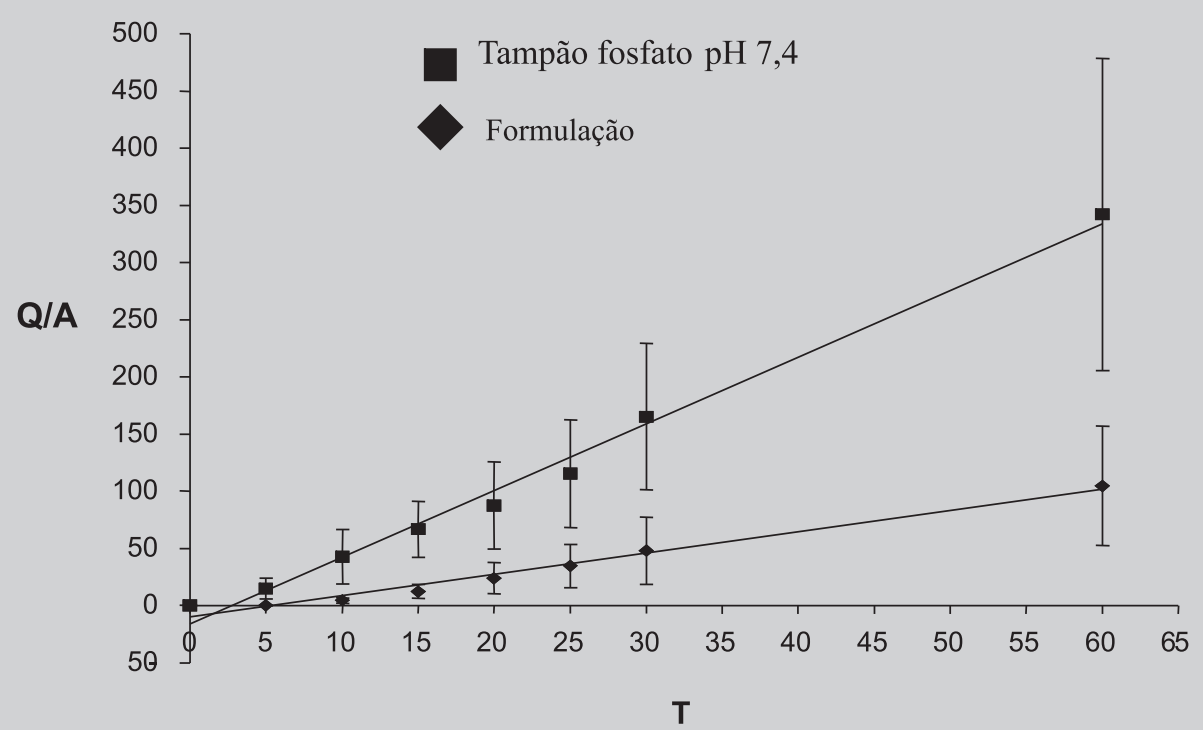

Legenda: $\mathrm{T}=$ Tempo (minutos); $\mathrm{Q} / \mathrm{A}=$ Quantidade de ácido kójico permeado por área $\left(\mu \mathrm{g} / \mathrm{cm}^{2}\right), \mathrm{n}=4$ (Média $\left.\pm \mathrm{SD}\right)$ da formulação $\mathrm{F} 4$ e da solução tampão fosfato $\mathrm{pH} 7,4$.

FIGURA 2 - Representação gráfica para determinação do tempo LAG do ácido kójico na formulação e da solução tampão fosfato $\mathrm{pH} 7,4$, nos ensaios de permeação cutânea in vitro.

A Tabela II relaciona os parâmetros cinéticos de permeação cutânea in vitro do ácido kójico presente nas duas formulações em estudo através do modelo de Higuchi (pseudo $1^{\mathrm{a}}$ ordem), do modelo de cinética de $1^{\mathrm{a}}$ ordem e do modelo de cinética de ordem zero.

O modelo cinético de ordem zero apresentou um maior coeficiente de correlação $(r=0,9891)$ para a formulação, no período de até 1 hora, indicando que o fluxo, neste intervalo, independe da concentração do fármaco. Este modelo cinético é característico de formulações com doses infinitas (Wester, Maibach, 1989).

Porém, após a primeira hora o sistema sofreu uma alteração na cinética, passando a ser de pseudo $1^{\text {a }}$ ordem (modelo de Higuchi), conforme mostra o coeficiente de correlação $(r=0,9943)$ na Tabela II. Este modelo cinético, comum em suspensões, determina que o fluxo depende da concentração do fármaco disponível. Deste modo, verifica-se que ocorreu um esgotamento do fármaco em contato com a membrana, passando a permear o fármaco em suspensão na formulação (Chow, Kaka, Wang, 1984).

Em relação à solução tampão fosfato $\mathrm{pH} 7,4$, observa-se que esta apresenta coeficiente de correlação $(\mathrm{r}=0,9983)$ maior para a cinética de ordem zero (Tabela II). Este resultado condiz com a quantidade de fármaco presente na solução tampão fosfato $\mathrm{pH} 7,4$ e com o fato deste estar solubilizado no meio (Flynn, 1989), não alterando o fluxo com o decorrer do tempo (Figura 2).

Nos estudos in vitro de produtos dermatológicos é importante considerar que as concentrações de fármacos na solução receptora, por si só, não refletem a influência da formulação na atividade do produto. Assim, a determinação da quantidade de fármaco retido na membrana leva

TABELA II - Parâmetros cinéticos das curvas de permeação in vitro do ácido kójico na formulação e na solução tampão fosfato $\mathrm{pH} 7,4$

\begin{tabular}{lccc}
\hline Formulação & Modelo Higuchi & Cinética de ordem zero & Cinética de $1^{\mathrm{a}}$ ordem \\
& $\mathrm{J}\left(\mu \mathrm{g} / \mathrm{cm}^{2} / \mathrm{min}\right) \mathrm{r}$ & $\mathrm{J}\left(\mu \mathrm{g} / \mathrm{cm}^{2} / \mathrm{min}\right) \mathrm{r}$ & $\mathrm{J}\left(\log \mu \mathrm{g} / \mathrm{cm}^{2} / \mathrm{min}\right) \mathrm{r}$ \\
\hline F 4 - até 1 hora & $14,86220,962952$ & $1,1963530,989118$ & $0,0649470,95700$ \\
F4 - de 1 a 8 horas & $81,5910,994313$ & $29,71710,930774$ & $0,270980,70399$ \\
Solução tampão fosfato $\mathrm{pH} 7,4$ & $0,1010,970742$ & $4,039040,998334$ & $876,19460,98892$ \\
\hline
\end{tabular}

Legenda: J = Fluxo; $r$ = coeficiente de correlação linear. 
a dados mais concretos, os quais podem elucidar o grau de atividade tópica do produto (Masini et al., 1993).

\section{Retenção cutânea}

A determinação por espectrometria no ultravioleta do ácido kójico retido na pele da orelha de porco foi realizada após a extração direta em metanol. Este procedimento apresentou-se adequado, uma vez que o fármaco é solúvel em metanol e os componentes da pele de orelha de porco e da fita adesiva que também foram extraídos não interferiram no método analítico.

Para a determinação do teor de ácido kójico retido foi utilizada curva analítica em metanol, no comprimento de onda de $269 \mathrm{~nm}$.

A Tabela III mostra as médias dos valores de retenção cutânea do ácido kójico por grama de pele na formulação e na solução tampão fosfato $\mathrm{pH} 7,4$, sendo que a formulação promoveu significativamente $(\mathrm{p}<0,01)$ maior retenção cutânea que a solução tampão fosfato $\mathrm{pH} 7,4$.

A solução tampão fosfato $\mathrm{pH}$ 7,4 apresentou retenção cutânea menor (Figura 3), possivelmente devido ao fato desta não possuir nenhuma lipofilia, dificultando a interação do produto com os lipídios presentes na pele (Sethi, Agha, 1993).

No entanto, na formulação houve retenção cutânea significativamente $(\mathrm{p}<0,01)$ maior em comparação à solução tampão fosfato $\mathrm{pH} 7,4$. Isto ocorreu provavelmente porque os componentes de uma emulsão, por exemplo os tensoativos e os lipídios, apresentam afinidade e/ou
TABELA III - Retenção cutânea do ácido kójico na formulação e na solução tampão fosfato $\mathrm{pH} 7,4$, determinada por espectrofotometria no ultravioleta $(269 \mathrm{~nm})$

\begin{tabular}{lc}
\hline Retenção cutânea & Média $(\mu \mathrm{g} / \mathrm{g}) \pm \mathrm{DP}$ \\
\hline Formulação & $39852,51 \pm 1510,40$ \\
Solução tampão fosfato $\mathrm{pH} 7,4$ & $13643,95 \pm 479,77$ \\
\hline
\end{tabular}

NOTA: Como branco foi utilizado uma formulação isenta de ácido kójico e uma solução tampão fosfato pH 7,4.

interação com os constituintes da membrana, demonstrando as vantagens deste tipo de formulação para produtos de uso dermatológico (Florence, Atwood, 2003).

A contribuição do estudo de permeação in vitro na avaliação de propriedades farmacocinéticas de formulações e no desenvolvimento farmacotécnico é inquestionável, pois representa um procedimento prático, rápido e de baixo custo. Os estudos in vitro também encontram aplicação no controle de qualidade de uniformidade de lotes de produtos dermatológicos na indústria farmacêutica. Entretanto, deve-se ter a cautela quanto à extrapolação dos resultados obtidos para situações in vivo. Com a metodologia in vitro pode-se fazer uma seleção prévia das formulações antes da realização de testes clínicos.

A formulação apresentou dois comportamentos cinéticos. No período de até 1 hora há um fluxo com característica cinética de ordem zero e no período de 1 a 8

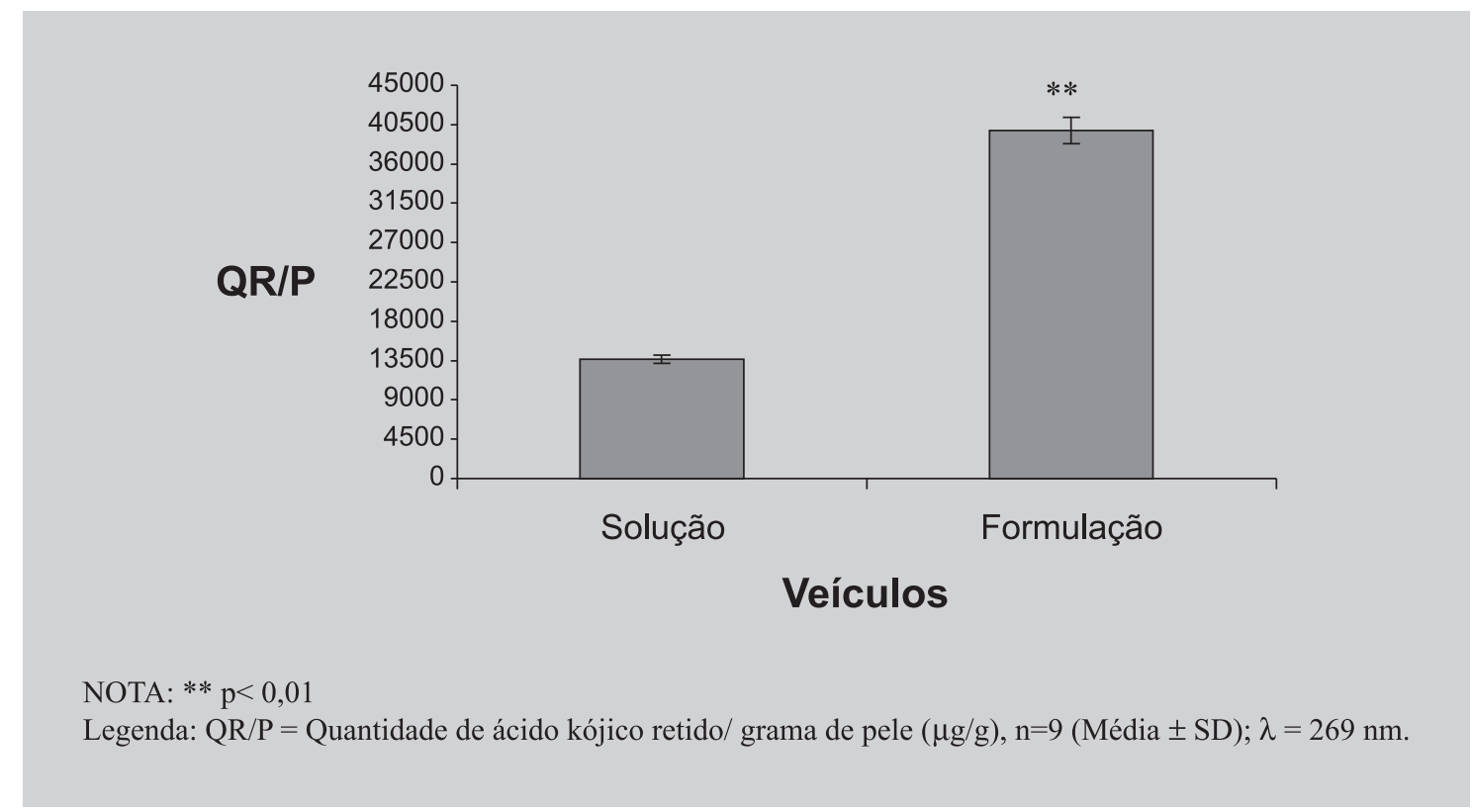

FIGURA 3 - Quantidade de ácido kójico retido na pele da orelha de porco após 8 h de contato com os veículos. 
horas cinética de pseudo $1^{\mathrm{a}}$ ordem. Isto possivelmente ocorreu porque em um primeiro momento o fármaco encontra-se em contato direto com a membrana e nas horas subseqüentes o fluxo é dependente também da difusão do fármaco da própria formulação.

Em solução tampão pH 7,4, o ácido kójico apresentou um fluxo pela membrana característico de cinética de ordem zero. Isto provavelmente ocorreu porque todo o fármaco está solubilizado no meio e conseqüentemente disponível para a permeação.

Comparando as cinéticas da formulação com a da solução tampão $\mathrm{pH}$ 7,4 verifica-se a vantagem do uso da formulação devido à permeação desta ser menor.

\section{CONCLUSÃO}

A formulação mostrou-se adequada para veicular o ácido kójico, pois apresentou as características desejáveis de um produto para uso tópico, ou seja, grande retentividade e pequena permeabilidade.

\section{ABSTRACT}

\section{Kojic acid in vitro percutaneous penetration study}

Disorder of the tirosinase biosynthesis process can result on hiperpigmentations, like the frequently found melasma. The kojic acid is one of the depigmenting topic agent utilized in the handling of these hipercromies. The action of a dermatologic product should be topic, should not reach systemic levels. One of the factors that is able to defined the level of action, topic or systemic, is the vehicle. In this contest, the present work had for objective evaluate the rank of in vitro cutaneous permeation, in the cell of FRANZ modified, of a formulation regarding a buffered solution 7.4, both containing kojic acid (2\%). The kojic acid percutaneous penetration and retention was quantified by a spectrophotometric in the ultraviolet method. The in vitro study showed that the absorption of kojic acid from the formulation presented kinetic of pseudo $1^{\text {st }}$ order (in the break from 1 to 8 hours) and consequently smaller stream through the natural membrane (skin from the ear of pig) and bigger cutaneous retention, while the kojic acid from the buffered solution pH 7.4 presented kinetic of zero order and consequently bigger stream and smaller retention. This result indicated that the formulation developed can be used as a vehicle for kojic acid, having in mind that the target tissue is the skin.

\section{REFERÊNCIAS BIBLIOGRÁFICAS}

ANSEL, H.C.; POPOVICH, N.G.; ALlEN, L.V. Farmacotécnica, formas farmacêuticas e sistemas de liberação de fármacos. 6 ed. São Paulo: Editorial Premier, 2000. p. 300-301.

ARONSON, H. Correction factor for dissolution profile calculations. J. Pharm. Sci., Washington, v. 82, n. 11, 1993.

BATISTUZZO, J.A.O.; ITAYA, M.; ETO, Y. Formulário médico farmacêutico. 3.ed. São Paulo: Pharmabooks, 2006. 729p.

BENTLEY, M.V.L.B.; LOPEZ, R.F. V. Curso de permeação cutânea in vitro II. Módulo II. Apostila. Ribeirão Preto: FUNDEFARP, 2002. n.p.

BRONAUGH, R.L.; STEWART, R.F.; Methods for in vitro percutaneous absorption studies IV: preparation of the barrier layer. J. Pharm. Sci., Washington, v. 75, n. 5, p. 487-491, 1986.

BRONAUGH, R.L.; MAIBACH, H.I. Percutaneous absorption: Drugs - cosmetics - mechanisms methodology. 3.ed. New York: Marcel Dekker, 1999. v. 97.955 p.

CHOW, D.S.L.; KAKA, I.; WANG, T.I. Concentrationdependent enhancemente of 1-dodecylazacycloheptan2-one, on the percutaneous penetration kinetics of triamcinolone acetonde. J. Pharm. Sci., Washington, v. 73, n. 12, p. 1794-1799, 1984.

ELLIS, D.A.F.; TAN, A.K.W.; ELLIS, C.S. Superficial micropeels: glicolic acid and alpha-hidroxy acid with kojic acid. F. P. Surg., New York, v. 11, n. 1, p. 15-21, 1995.

FLORENCE, A.T.; ATTWOOD, D. Principios físico químicos em farmácia. São Paulo: Edusp, 2003. 732p.

FLYNN, G.L. Mechanism of percutaneous absorption from physicochemical evidence. In: BRONAUGH, R. L.; MAIBACH, H. I., (Ed.). Percutaneous absorption: mechanisms, methodology, drug delivery. 2 ed. New York: Marcel Dekker, 1989. p. 37.

UNITERMS: In vitro cutaneous permeation. Kojic acid.

Depigmenting agent. 
GOMARA, F.L. Estudo de permeação cutânea in vitro do ácido kójico. Curitiba, 2003.125f. [Dissertação de Mestrado em Ciências Farmacêuticas. Universidade Federal do Paraná].

GOMARA, F.L.; CORRER, C.J.; SATO, M.E.O.; PONTAROLO, R. Desarrollo y validación de un método espectrofotométrico para cuantificacion de ácido kójico. Ars Pharm., Barcelona, v. 45, n. 2, p. 145-153, 2004.

LACHMAN, L.; LIEBERMAN, H.A.; KANIG, J.L. Teoria e prática na indústria farmacêutica. Lisboa: Fundação Calouste Gulbenkian, 2001.539p.

MASINI, V.; BONTE, F.; MEYBECK, A.: WEPIERRE, J. Cutaneous bioavailability on hairless rats of tretinoin in liposomes or gel. J. Pharm. Sci., Washington, v. 82, n. 1, p. 17-21, 1993.

MICHNIAK, B.B.; CHAPMAN, J.M.; SEYDA, K.L. Facilitated transport of two models steroids by esters and amides of clofibric acid. J. Pharm. Sci., Washington, v. 82, n. 2, 214-219, 1993.

OECD Guidance document for the conduct of skin absorption studies. Paris: Organisation for economic cooperation and development, 2004. n.p.

PALUDETTI, A.L. Formulando em dermocosmética. Cosmet. Toilet., São Paulo, v. 7, p. 26-29, 1995.

PRISTA, L.N.; BAHIA, F.G.M.; VILAR, E. Dermofarmácia e cosmética. Porto: Associação Nacional das Farmácias, 1992. p. 145-150.

REIFENRATH, W.G. et al. Percutaneous penetration in the hairless dog, weanlihg pig an grafted athymic nude mouse: evaluation of models for predicting skin penetration in man. Br. J. Dermatol., Oxford, v. 27, p. 123135, 1984.

SANCTIS, D.S. Emulsões aspectos técnicos e práticos para o desenvolvimento de formulações. Rev. Racine, São Paulo, p. 51, 2000.

SASAKI, H. et al. Enhancing effect of pyrrolidone derivatives on transdermal penetration of 5-fluorouracil, triamcinolona, acetonide, indomethacin and flubiprofen. J. Pharm Sci., Washington, v. 80, n. 6, p. 533-538, 1991.
SATO, K.; SUGIBAYASHI, K.; MORIMOTO, Y. Species differences in percutaneous absorption of nicorandil. $J$. Pharm. Sci., Washington v. 80, p. 104-107, 1991.

SCHUELLER, R.; ROMANOWSKI, P. Emulsões. Cosmet. Toilet., São Paulo, v. 12, p. 71-74, 2000.

SETHI, P.K.; AGHA, B.J. In vitro human cadaver skin retention and penetration of a lipophilic compound. Pharm. Res., New York, v. 10, n. 10, Suppl., PDD 7309, 1993.

SHAH, V.P.; BEHL, C.R.; FLYNN, G.L.; HIGUCHI, W.I.; SCHAEFER, H. Principles and criteria in the development and optimization of topical therapeutic products. Int. J. Pharm., Amsterdam, v. 82, p. 21-28, 1992 (a).

SHAH, V.P.; ELKINS, J.; SKELLY, J P. Relationship between in vivo skin blanching and in vitro release rate for betamethasone valerato creams. J. Pharm Sci., Washington, v. 81, n. 1, p. 104-106, 1992 (b).

SHAH, V.P.; MAIBACH, H.I. Topical drug biovailability, bioequivalence, and penetration. New York: Plenum Press, 1993. 453p.

SMITH, E. W.; HAIGH, J.M. In vitro systems for assessment of drugs release from topical formulations and transmembrane permeation. In: BRONAUGH, R. L.; MAIBACH, H. I. Percutaneous absorption: mechanisms, methodology, drug delivery. 2 ed. New York: Marcel Dekker, 1989. p. 465-508.

TAUBER, U.; TODA, T. Biotransformation of Diflucortolon - vareriato in hairless mouse membrane. ArzneimForsch., Aulendorf, v. 26, n. 7b, p. 1484-1487, 1976.

WESTER, R.C.; MAIBACH, H. I. In vitro testing of topical pharmaceutical formulations. In: BRONAUGH, R.L.; MAIBACH, H.I. Percutaneous absorption: mechanisms, methodology, drug delivery. New York: Marcel Dekker, 1989. p. 653-659.

Recebido para publicação em 30 de novembro de 2004. Aceito para publicação em 20 de abril de 2007. 